\title{
LETTER
}

\section{Lung reaeration after surfactant instillation - caused by surfactant or caused by instillation?}

\author{
Marcus J Schultz ${ }^{* 1-3}$ \\ See related research by Lu et al., http://ccforum.com/content/14/4/R135
}

In this issue of Critical Care, Lu and colleagues [1] report significant and prolonged lung reaeration after intratracheal bolus instillation of porcine-derived surfactant. In this substudy of a larger randomized controlled trial of patients with acute lung injury [2], the investigators elegantly demonstrate increased volumes of gas in poorly and non-aerated lung of patients who were treated with surfactant as compared with patients who received routine care.

Do these encouraging findings truly support the rationale for exogenous surfactant replacement as an indication for lung reaeration in patients with acute lung injury? This can be questioned. First, intratracheal bolus instillation of surfactant required recruitment maneuvers. Indeed, larger tidal volumes (TVs) and higher levels of positive end-expiratory pressure (PEEP) were used for as long as 30 minutes after instillation of surfactant to each lung. The instillation procedure per se could be (solely) responsible for increased volumes of gas in poorly and non-aerated lung.

In addition, bolus instillation of surfactant resulted in temporarily severe hypoxemia in more than half of the patients treated with surfactant [2]. Though not reported in the original study or the present study, rescue therapies such as prone ventilation, repeated recruitment maneuvers, and higher levels of PEEP could have been used more intensively in these patients. These rescue maneuvers, in response to surfactant instillation-induced hypoxemia, could also be responsible for the findings by Lu and colleagues [1].

\section{Authors' response}

Qin Lu and Jean-Jacques Rouby

We thank Dr Schultz for his interest in our study [1]. We cannot agree, however, with his hypothesis that lung reaeration after surfactant replacement resulted solely from recruitment maneuver and high PEEP used after instillation procedure.

Surfactant replacement consisted of the intratracheal injection of a large bolus of surfactant followed by five consecutive TVs of $12 \mathrm{~mL} / \mathrm{kg}$ associated with a PEEP of $5 \mathrm{cmH}_{2} \mathrm{O}$. Then, TV was reduced to $6 \mathrm{~mL} / \mathrm{kg}$, and for 30 minutes, PEEP was set $5 \mathrm{cmH}_{2} \mathrm{O}$ above the preinstillation level (range of 12 to $17 \mathrm{cmH}_{2} \mathrm{O}$ ). Mechanical ventilation with pre-instillation $\mathrm{TV}$ and PEEP was subsequently resumed [2]. Such changes in ventilator settings in no way can be considered 'recruitment maneuvers' with the potential of inducing significant

*Correspondence: m.j.schultz@amc.uva.nl

'Department of Intensive Care Medicine, Academic Medical Center,

Meibergdreef 9, 1105 AZ Amsterdam, The Netherlands

Full list of author information is available at the end of the article alveolar recruitment. In addition, it is well known that 'true' recruitment maneuvers, like continuous positive airway pressure of $40 \mathrm{cmH}_{2} \mathrm{O}$ for 40 seconds, result in alveolar recruitment and improvement of oxygenation lasting less than 30 minutes [3]. In our study, a significant increase of gas volume in poorly and non-aerated lung regions was observed 5 days after surfactant replacement. This long-lasting effect can hardly be explained by ventilator setting changes that cannot be considered recruitment maneuvers and that were performed several days ago. Also, it should be pointed out that prone position and repeated recruitment maneuvers were not used and that PEEP levels between surfactant and control groups over the period of mechanical ventilation were not different. Therefore, lung reaeration measured in our study can be ascribed solely to surfactant replacement.

\section{Abbreviations}

PEEP, positive end-expiratory pressure; TV, tidal volume.

Competing interests

The author declares that he has no competing interests. 


\section{Author details}

'Department of Intensive Care Medicine, Academic Medical Center, Meibergdreef 9, 1105 AZ Amsterdam, The Netherlands. 'Laboratory of Experimental Intensive Care and Anesthesiology $\left(\left.L^{*} E^{*}\right|^{*} C^{*} A\right)$, Academic Medical Center, Meibergdreef 9, 1105 AZ Amsterdam, The Netherlands. ${ }^{3}$ HERMES Critical Care Group, Amsterdam, The Netherlands.

Published: 20 August 2010

\section{References}

1. Lu Q, Zhang M, Girardi C, Bouhemad B, Kesecioglu J, Rouby JJ: Computed tomography assessment of exogenous surfactant-induced lung reaeration in patients with acute lung injury. Crit Care 2010,14:R135.

2. Kesecioglu J, Beale R, Stewart TE, Findlay GP, Rouby JJ, Holzapfel L, Bruins P,
Steenken EJ, Jeppesen OK, Lachmann B: Exogenous natural surfactant for treatment of acute lung injury and the acute respiratory distress syndrome. Am J Respir Crit Care Med 2009,180:989-994.

3. Oczenski W, Hormann C, Keller C, Lorenzl N, Kepka A, Schwarz S, Fitzgerald RD: Recruitment maneuvers after a positive end-expiratory pressure trial do not induce sustained effects in early adult respiratory distress syndrome. Anesthesiology 2004,101:620-625.

doi:10.1186/cc9211

Cite this article as: Schultz MJ.: Lung reaeration after surfactant instillation caused by surfactant or caused by instillation? Critical Care 2010, 14:437. 